OPEN ACCESS

Edited by:

Luigi Janiri,

Catholic University of the Sacred, Italy

Reviewed by:

Chiara Montemitro,

G. d'Annunzio University of Chiet

and Pescara, Italy

Marco Di Nicola,

Agostino Gemelli University Polyclinic,

Italy

*Correspondence:

Morgane Guillou Landreat morgane.guillou@chu-brest.fr

Specialty section: This article was submitted to

Addictive Disorders,

a section of the journal

Frontiers in Psychiatry

Received: 24 May 2019 Accepted: 22 October 2019 Published: 25 November 2019

Citation:

Guillou Landreat M, Cholet J, Grall Bronnec M, Lalande S and Le Reste JY (2019) Determinants of Gambling Disorders in Elderly People-A Systematic Review.

Front. Psychiatry 10:837. doi: 10.3389/fpsyt.2019.00837

\section{Determinants of Gambling Disorders in Elderly People-A Systematic Review}

\author{
Morgane Guillou Landreat ${ }^{1 *}$, Jennyfer Cholet ${ }^{2}$, Marie Grall Bronnec ${ }^{2,3}$, Sophie Lalande ${ }^{4}$ \\ and Jean Yves Le Reste ${ }^{5}$ \\ ${ }^{1}$ EA 7479 SPURBO, Department of Addiction Disorders, Université de Bretagne Occidentale, Brest, France, ${ }^{2}$ Addictive \\ Disorders Unit, University Hospital of Nantes, Nantes, France, ${ }^{3} E A$ 4275, Faculté de Médecine de Nantes, Nantes, France, \\ ${ }^{4}$ EA 7479, Department of Family Practice, Université de Bretagne Occidentale, Brest, France, ${ }^{5}$ ERCR SPURBO, Department \\ of Family Practice, Université de Bretagne Occidentale, Brest, France
}

Background: Despite the growth in the number of studies on gambling disorders (GDs) and the potentially severe harm it may cause, problem gambling in older adults is rarely apparent in literature. Driven by the need to overcome this limitation, a broad systematic review is essential to cover the studies that have already assessed the determinants of $\mathrm{GD}$ in the elderly.

Objectives: The aim of this systematic review is to understand the determinants related to GDs in elderly people.

Methods: A total of 51 studies met the inclusion criteria, and data were synthesized.

Results: Three major types of determinants were identified in this review: individual, socio-financial and environmental.

Conclusions: This review explored the determinants influencing GDs in older people. The findings are relevant to academics, policymakers, patients, and practitioners interested in the identification and prevention of GD in older people.

Keywords: elderly, aged, problem gambling, pathological gambling, gambling disorder, behavioral addictions, public health, review article

\section{INTRODUCTION}

\section{Rationale}

Gambling is a popular activity among older people and this is cross-cultural (1). Gambling participation is increasing significantly among the elderly and it is becoming a particularly widespread and regular recreational behavior among this population (2). In the United States, the participation rate in gambling among older people, over the preceding year, increased from $23 \%$ to $50 \%$, between 1975 and $1998(3,4)$. Older adults generally possess positive attitudes towards gambling activities (5). Gambling is considered a harmless form of entertainment, whereas it was considered a vice in the first part of the 20th century (6). The rates for older adults' participation in gambling, in the preceding year, ranged from $26.6 \%$ to $85.6 \%(7-10)$. The prevalence of problem gambling among older people ranges from $0.3 \%$ to $10.4 \%$ in studies of those over 55 years of age (3). Among those over 60 years of age, Subramaniam et al. found a life-long prevalence of problem gambling of between $0.01 \%$ and $10.6 \%$ in a systematic review (1).

Abbreviations: GD, Gambling disorder. 
In literature, a great deal of research has focused on a younger age group and on the "classic " problem gambler, especially the middle-aged man $(2,11)$. A broad range of risk factors for GD in young adults has been documented, including sociodemographic characteristics (male gender, younger age, low socioeconomic status) $(12,13)$, gambling habits (early exposure, availability) (14) or individual vulnerabilities such as negative life events, personal psychiatric/addictive comorbidity (15), or familial history of GD or substance use disorders $(16,17)$. More specifically, many studies on GD in adults investigated cognitive distortions which are related to an inability to control or to stop gambling $(18,19)$. Craving is an urge to participate in gambling and decreased cognitive control was identified in GD which correlated in fMRI with impaired activity in the prefrontal cortex (20). Reward system dysfunction was also identified in adults with GD, compared with a control group, with striatal presynaptic dysfunction (21). This point is interesting in that Dreher at al. directly demonstrated a tight coupling of midbrain dopamine synthesis and reward-related prefrontal cortex activity; they provided direct evidence for an alteration of this regulatory relationship in healthy older humans (22).

Vulnerable populations, such as elderly people, remain rare subjects in literature. However, regular gambling habits may cause potentially very serious harm: financial, social, familial, and other problems, even suicide $(11,23)$. Previous reviews on gambling disorders (GDs) have not focused exclusively on older people, and most of the studies had been conducted in North America: United States or Canada. Very few had been conducted in Europe.

Focusing on GDs in older adults is important, especially in order to characterise GD specificities in older adults. Several authors agree that the associated harm within this age group requires special attention (1).

\section{Objective}

In summary, this systematic review aims to provide a broad, cross-cultural picture of the determinants of GDs in older adults. Accordingly, we reviewed both qualitative and quantitative studies that included older patients with GD.

\section{METHODS AND MATERIALS}

\section{Protocol, Registration, and Eligibility Criteria}

The current systematic review focuses on elderly individuals with GDs and is based on qualitative and quantitative studies that describe clinical particularities. The PRISMA statement for reporting systematic reviews was adopted. The protocol had not previously been registered for this review. Inclusion criteria were coded by both authors reaching an agreement regarding the coding process and were: (a) including clinical samples of GD in those aged 65+; (b) containing quantitative and/or qualitative data; (c) being published in a peerreviewed journal; (d) being available as a full text in one of the following languages (spoken languages of the authors): English or French.

\section{Information Sources and Search Strategy}

Existing papers were identified by searching the academic databases PubMed and PsycINFO, from March to May 2018, published from January 1990 to February 2018. Both authors drew up a list of agreed English keywords for the systematic search: Gambling (MeSH term) OR "Gambling disorder" OR "problem gambling" OR "Pathological gambling" AND "Aged (MeSH term)" OR Aged 80+ (MeSH term) "elders" OR "older adults" in the title, abstract or keywords. Inclusion and exclusion criteria are presented in Table $\mathbf{1 .}$

\section{Study Selection and Data Collection Process}

At the first stage, 867 articles were identified with the key words Gambling (MeSH term) OR "Gambling disorder" OR "problem gambling” OR "Pathological gambling” AND "Aged (MeSH term)" OR Aged 80+ (MeSH term) "elders" OR “older adults". At the second stage, duplicated papers were excluded. The selection of papers for the systematic review was based on the inclusion and exclusion criteria previously described. Following the search strategy presented in the flow diagram in Figure 1, the inspection of article titles and abstracts concluded with the inclusion of a total of 51 papers. We included studies or literature reviews in the English or French languages, which concerned older people (over 50 years of age) specifically, in clinical settings, and those which concerned gamblers (with or without problems). We excluded neurocognitive studies and experimental studies. (See inclusion and exclusion criteriaTable 2). We excluded studies on the general population, even when such studies included older people up to 85 years of age. Older gamblers represented a small part of these populations and so no specific analysis was carried out on these subgroups in general population studies.

\section{Data Extraction and Quality Assessment}

Considering the exploratory nature of this systematic review, and in order to have a broad understanding of GD in the elderly, the studies were not filtered according to their quality and both qualitative and quantitative studies were taken into consideration. Given the high levels of heterogeneity of the data across studies, as regards research methods, data were synthesized qualitatively through a summary table and a narrative synthesis using these categories: (1) the individual determinants; (2) the structural determinants; (3) the environmental determinants.

TABLE 1 | Inclusion and exclusion criteria.

\begin{tabular}{ll}
\hline Inclusion criteria & Exclusion criteria \\
\hline Population & \\
older people over 50 years of age & no participants over 65 years of age
\end{tabular}

older people over 50 years of age

gambling or problem gambling

Study design

published qualitative or quantitative

studies or case reports

Countries, date, language

January 1990-February 218 studies other languages

reported in English or French 


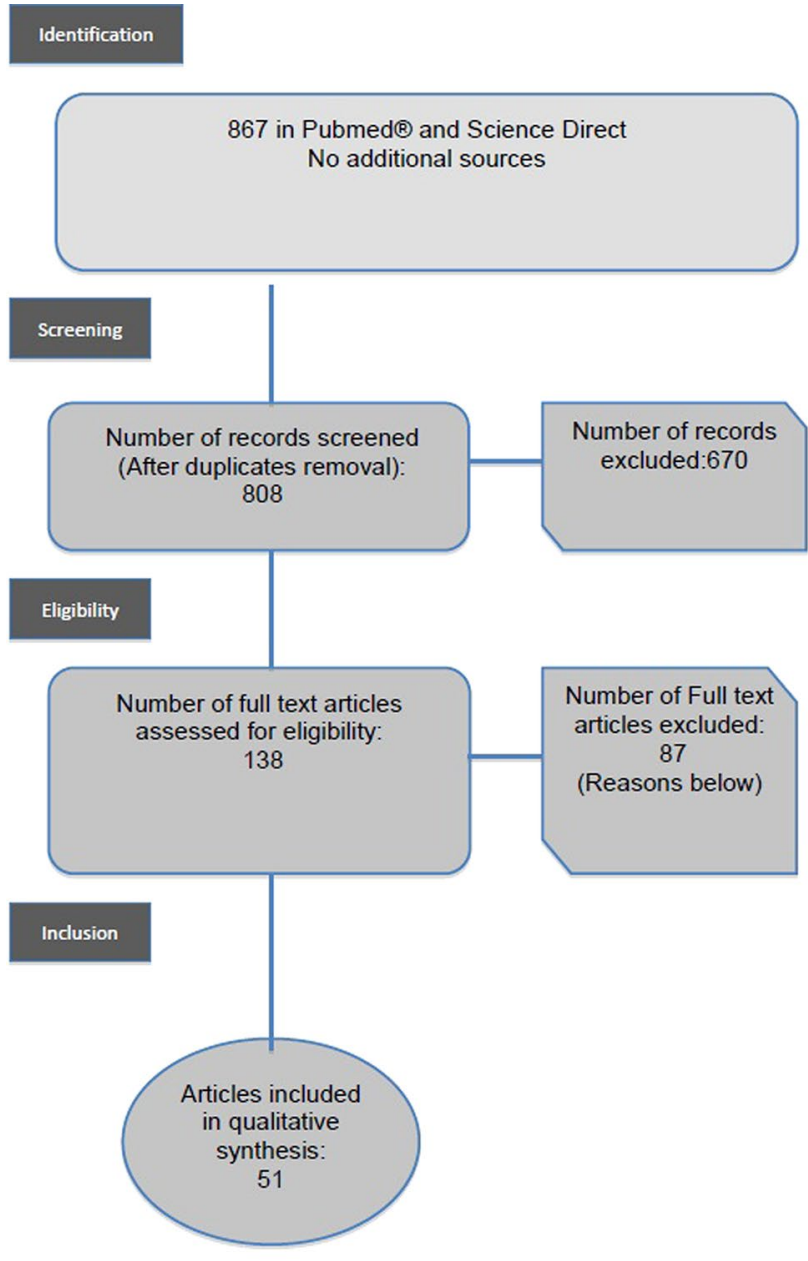

FIGURE 1 | Prisma diagram.

\section{RESULTS}

\section{Study Selection and Characteristics}

In this review, the first group of 867 papers was identified by searching for the keyword in the scientific database. As described in the flow diagram (Figure 1), 670 papers were excluded because they were replicated records or because the topic was not GD in elderly people. One hundred thirty-eight were assessed for eligibility, 87 full texts were excluded because they did not describe clinically elderly persons with GD. A total of 51 studies met the inclusion criteria. The publication dates ranged from 1990 to 2018 and contained clinical samples of elderly persons with GD. Selected articles are listed in Table 2.

\section{Risk of Bias Within Studies Selection Bias}

The definition of older adults significantly differed in literature: 12 articles specified those over 50 or 55 years of age $(3,9,10$, 24-32); 16 articles, those over 60 years of age (1, 2, 5, 33-45); 16 articles, those over 65 years of age $(32,46-60)$, and 7 over
70 years of age (8). Methodologically, these differences in age criteria bring difficulties in comparing and analyzing data from the literature.

\section{Evaluation Bias}

Gambling becomes a problem when gambling behavior becomes persistent, recurrent, and leads to clinically significant difficulties (61). The diagnostic criteria for pathological gambling are constructed and validated for the middle-aged adult in employment. Several criteria lose their specificity in ageing subjects: loss of social activities, damage to career, and harm to those close to them, are far less relevant to retired people who are alone or isolated for reasons other than those related to gambling behavior (62).

\section{Cultural Bias}

A large majority were conducted in North America (USA or Canada), Australia, or Singapore but only a few articles concerned Europe (six articles).

\section{Synthesis of the Results}

Articles are presented in Table 2. 3 Themes were mainly identified (Figure 2)

This review focuses on: (1) individual determinants, (2) structural determinants, (3) environmental determinants of GD in the elderly.

\section{Individual Determinants}

Gender influences gambling habits. Women over the age of 60 have a risk of problem gambling that is equivalent to, or even higher than, that of men in the same age group (20). The prevalence of at-risk or problem gamblers (between 1 and 4 in the criteria for pathological gambling) is high among women over 65 years of age (20).

Age at gambling initiation is a risk factor for more frequent and more severe gambling behavior, as well as for pathological gambling in later life $(3,21)$. However, where a more advanced age is concerned, most studies found that the prevalence of problem gambling declined with age beyond 60 . Ladd et al. conducted a study among gamblers over 65 years of age and found problem gamblers were significantly younger than non-problem gamblers (22).

\section{Comorbidities}

In elderly subjects with gambling problems, more significant medical or psychosocial comorbidities are reported than in nongamblers or non-problem gamblers (1). These connections are multifactorial. Gambling is a sedentary activity, which can lead to medical problems (23) or, conversely, it can attract people who already have difficulty moving around for medical reasons. People with alcohol use disorder or tobacco use disorder, whose general health is impaired, may seek relaxation or excitement from readily available gambling opportunities (1). Moreover, the practice of gambling is in itself a stress factor. Several studies have shown neurophysiological changes (hyper-reactivity of the autonomous system in response to gambling-related stimuli) and neurochemical changes (elevated levels of cortisol, norepinephrine, and dopamine during casino gambling sessions). These changes may increase the risk of chronic pathologies (51). 
TABLE 2 | Article synthesis.

\begin{tabular}{|c|c|c|c|c|c|}
\hline Country & Author & Year & N/Age median & Type of study & Main findings \\
\hline \multicolumn{6}{|c|}{ Literature review } \\
\hline \multirow[t]{3}{*}{ France } & $\begin{array}{l}\text { Guillou Landreat } \\
\text { M. et al }\end{array}$ & 2017 & $55+$ & Literature review & GD: the main behavioral addiction in the elderly. \\
\hline & & & & & Underestimation of GD in the elderly \\
\hline & & & & & $\begin{array}{l}\text { Treatment target: person's quality of life and ability } \\
\text { to regain control }\end{array}$ \\
\hline France & Luquiens & 2017 & & $\begin{array}{l}\text { Communication } \\
\text { report }\end{array}$ & $\begin{array}{l}\text { GD: a public health problem, lack of diagnosis } \\
\text { criteria }\end{array}$ \\
\hline Canada & Mc Kay et al. & 2005 & $55+$ & Literature review & $\begin{array}{l}\text { Age/gender/gambling industry marketing } \\
\text { strategies and slot machines (EGM): heightened } \\
\text { risk for developing PG with EGMs in older women }\end{array}$ \\
\hline Singapore & Subramaniam et al. & 2015 & $60+$ & Literature review & GD: $0.01 \%$ to $10.6 \%$ of GD \\
\hline Australia & $\begin{array}{l}\text { Tirachaimongkol } \\
\text { et al., }\end{array}$ & 2010 & $55+$ & Literature review & $\begin{array}{l}3 \text { clusters of risk factors: individual (distressing } \\
\text { situations - refusal to seek help or impose barriers } \\
\text { to gambling)/socio-environmental (unsupportive } \\
\text { environment, cognitive distortions and incentives } \\
\text { or misleading advertisements)/behavioral } \\
\text { regulation factors (disinhibition, impaired decision } \\
\text { making, risk taking) }\end{array}$ \\
\hline Singapore & Tse et al. & 2012 & $55+$ & Literature review & $\begin{array}{l}\text { Several limitations: cultural, instrument, lack of } \\
\text { empirical research, lack of qualitative study, lack of } \\
\text { data on protective factors and positive outcomes, } \\
\text { limited in terms of types of gambling studied }\end{array}$ \\
\hline USA & Wick & 2012 & $65+$ & Literature review & $\begin{array}{l}\text { Gambling social activity for } 80 \% \text { elderly Elderly } \\
\text { vulnerable to financial instability. Aged } 65+=39 \% \\
\text { to } 45 \% \text { of casino traffic }\end{array}$ \\
\hline \multicolumn{6}{|c|}{ Qualitative study } \\
\hline Quebec & Papineau et al. & & $N=1465+$ & Qualitative study & $\begin{array}{l}\text { Prevalence comparable to younger gamblers } \\
\text { Retirement and social changes: risk factors Higher } \\
\text { financial impact Specific therapeutic targets: } \\
\text { cognitive/social/financial treatment, adapted to } \\
\text { older people }\end{array}$ \\
\hline UK & Pattinson et Parke & 2017 & $65+$ & Qualitative study & $\begin{array}{l}\text { Motivation factors: filling void/emotional escape/ } \\
\text { overspending }\end{array}$ \\
\hline Singapore & Subramaniam et al. & 2017 & $N=2560+$ & Qualitative study & $\begin{array}{l}\text { Gambling onset associated with family history } \\
\text { of gambling. Gambling = family activity Financial } \\
\text { damage in family and a significant motivating } \\
\text { factor for seeking treatment. }\end{array}$ \\
\hline Singapore & $\begin{array}{l}\text { Subramaniam M. } \\
\text { et al. }\end{array}$ & 2017 & $N=2560+$ & Qualitative study & $\begin{array}{l}\text { Gamblers described self-developed cognitive and } \\
\text { behavioral control strategies to limit gambling to } \\
\text { non-problematic levels-Comparable with middle- } \\
\text { aged adults' strategies }\end{array}$ \\
\hline Singapore & Subramaniam et al. & 2017 & $N=2560+$ & Qualitative study & $\begin{array}{l}\text { Cognitive distortions: illusion of control, near miss, } \\
\text { concept of luck, superstitious beliefs, entrapment, } \\
\text { gamblers' fallacy, chasing, belief that wins are } \\
\text { higher than losses - role in maintenance of } \\
\text { problem gambling }\end{array}$ \\
\hline Australia & Tira et al. & 2014 & $N=3155+$ & Qualitative study & $\begin{array}{l}3 \text { pathways: grief pathway with unresolved losses/ } \\
\text { habit pathway with habituation/dormant pathway } \\
\text { with pre-existing behavioral excess or impulsivity. } \\
\text { Unresolved losses + mismanagement of life } \\
\text { stresses = most significant predictors of late-life PG }\end{array}$ \\
\hline \multicolumn{6}{|c|}{ Case report } \\
\hline France & Sauvaget et al. & 2015 & $N=165+$ & Case report & $\begin{array}{l}\text { Online Gambling underestimated in the elderly due } \\
\text { to educational levels, shame, and medical and } \\
\text { psychiatric disorders }\end{array}$ \\
\hline \multicolumn{6}{|c|}{ Quantitative study or mixed method } \\
\hline USA & Black & 2017 & $N=17565+$ & Quantitative study & $\begin{array}{l}\text { Older PG: women, divorced, lower level of } \\
\text { education. Older gamblers more likely to have } \\
\text { sought PG treatment. }\end{array}$ \\
\hline Quebec & Boisvert et al. & 2012 & $N=5465+$ & $\begin{array}{l}\text { Mixed method: } \\
\text { Qualitative/ } \\
\text { quantitative study }\end{array}$ & $\begin{array}{l}\text { Gambling availability and characteristics (casino) } \\
\text { respond to specific needs of the elderly }\end{array}$ \\
\hline Australia & Botterill E. et al. & 2016 & $N=19365+$ & Quantitative Study & Loneliness predictor of PG in older adults for men \\
\hline
\end{tabular}


TABLE 2 | Continued

\begin{tabular}{|c|c|c|c|c|c|}
\hline Country & Author & Year & N/Age median & Type of study & Main findings \\
\hline USA & Burge et al. & 2004 & $N=5265+$ & Quantitative Study & $\begin{array}{l}\text { Gambling that begins in adolescence may be } \\
\text { associated with an elevated severity of problems } \\
\text { throughout life among older adult problem } \\
\text { gamblers }\end{array}$ \\
\hline USA & Christensen et al. & 2004 & $\begin{array}{l}\mathrm{N}=77+20 \\
\text { (qualitative } \\
\text { interview) } 50+\end{array}$ & $\begin{array}{l}\text { Mixed method } \\
\text { Quantitative/ } \\
\text { qualitative Study }\end{array}$ & $\begin{array}{l}\text { No correlations between gambling and health } \\
\text { perception }\end{array}$ \\
\hline New Zealand & Clarke D et al. & 2008 & $N=10465+$ & Quantitative study & $\begin{array}{l}\text { Gambling less severe but more frequently } \\
\text { Gambling severity correlated with motives for } \\
\text { releasing tensions }\end{array}$ \\
\hline Canada & Cousins et al. & 2007 & $N=44465+$ & Quantitative study & $\begin{array}{l}\text { At risk/bingo gambling: female, living in rental } \\
\text { accommodation, receiving federal income and } \\
\text { reporting health problems, and also sedentary: } \\
\text { predictors of more money spent on bingo. }\end{array}$ \\
\hline USA & Desai et al. & 2004 & $N=2,41765+$ & Quantitative study & $\begin{array}{l}\text { Recreational Gambling in older adults not } \\
\text { associated with negative measures of health and } \\
\text { well-being }\end{array}$ \\
\hline USA & Desai et al. & 2007 & $N=43,09365+$ & Quantitative study & $\begin{array}{l}\text { PG is associated with poorer health measures. } \\
\text { Recreational gambling was associated with } \\
\text { negative measures (obesity)+with positive } \\
\text { measures (mental and physical functioning) }\end{array}$ \\
\hline USA & Erickson et al. & 2017 & $N=34360+$ & Quantitative study & $\begin{array}{l}6.4 \% \text { problem gamblers, } 1.8 \% \text { pathological } \\
\text { gamblers. physical and psychological distress in } \\
\text { PG }\end{array}$ \\
\hline Finland & Joutsa et al. & 2014 & $N=57543-90$ & Quantitative study & 7\% PG Correlated with depression \\
\hline USA & Kausch et al. & 2004 & $N=3760+$ & Quantitative study & $\begin{array}{l}\text { psychiatric disorder, suicidal ideation comparable } \\
\text { to younger people }\end{array}$ \\
\hline USA & Kerber et al. & 2008 & $65+$ & Quantitative study & High level of psychiatric comorbidities \\
\hline USA & Kerber at al. & 2015 & $N=4065+$ & Quantitative study & $\begin{array}{l}\text { Gambling causing depression, being fired from a } \\
\text { job due to gambling, and still paying off gambling } \\
\text { debt }\end{array}$ \\
\hline USA & Ladd & 2003 & $N=49265+$ & Quantitative study & $\begin{array}{l}\text { Lifetime rates of PG: } 12.9 \% \text { in the bingo sample } \\
\text { and } 9.7 \% \text { in the senior center sample. } 39.1 \% \\
\text { reported gambling at least } 2 \times / \text { month, and } 33.7 \% \\
\text { wagered }>50 \text { dollars over the prior } 2 \text { months. }\end{array}$ \\
\hline Canada & Lai et al. & 2006 & $N=2,27255+$ & Quantitative study & $\begin{array}{l}26.6 \% \text { had gambled. Male, having lived in } \\
\text { Canada longer, a higher level of social support, } \\
\text { more service barriers, stronger level of Chinese } \\
\text { ethnic identity associated to higher probability of } \\
\text { gambling }\end{array}$ \\
\hline USA & Levens et al. & 2005 & $N=84365+$ & Quantitative study & $\begin{array}{l}69.6 \% \text { gambled in the past year. } 10.9 \% \text { at risk } \\
\text { gamblers }\end{array}$ \\
\hline USA & Martin et al. & 2011 & $N=24760+$ & Quantitative study & $\begin{array}{l}\text { Complex intrinsic and extrinsic motives for casino } \\
\text { venues: entertainment/win/money/allay boredom/ } \\
\text { loneliness }\end{array}$ \\
\hline USA Brazil & Medeiros et al. & 2015 & $N=7065+$ & Quantitative study & $\begin{array}{l}\text { Significant differences between } 2 \text { cultures: } \\
\text { gambling course, age of initiation, gambling } \\
\text { characteristics and behavior, personal history and } \\
\text { antecedents }\end{array}$ \\
\hline USA & McNeilly et al. & 2000 & $N=31565+$ & Quantitative study & $\begin{array}{l}\text { main motivations for gambling: relaxation, } \\
\text { boredom, passing time, and getting away for the } \\
\text { day }\end{array}$ \\
\hline Australia & Nower, Blaszcynski & 2008 & $N=1,60156+$ & Quantitative study & $\begin{array}{l}\text { Sex differences, women: telescoping effects, } \\
\text { Preference for non-strategic games. Fear of } \\
\text { suicide: a factor motivating self-exclusion }\end{array}$ \\
\hline UK & Parke et al. & 2018 & $N=59565+$ & Quantitative study & $\begin{array}{l}\text { Late-life PG: escape anxiety resulting from } \\
\text { deteriorating physical well-being/social support/ } \\
\text { induced depressive states }\end{array}$ \\
\hline USA & Petry & 2002 & $N=4955+$ & Quantitative study & $\begin{array}{l}\text { A minority of older PGST. Gender differences: } \\
\text { women = late age of regular gambling and } \\
\text { wagering high amounts }\end{array}$ \\
\hline Quebec & Philippe et al. & 2007 & $N=81055+$ & Quantitative study & $\begin{array}{l}\text { At-risk gambling: } 1.6 \% \text { Pathological gambling: } \\
1.2 \%\end{array}$ \\
\hline
\end{tabular}


TABLE 2 | Continued

\begin{tabular}{|c|c|c|c|c|c|}
\hline Country & Author & Year & N/Age median & Type of study & Main findings \\
\hline USA & Pietrzak et al. & 2007 & $\begin{array}{c}N=10,563 \\
60+\end{array}$ & Quantitative study & $\begin{array}{l}\text { Lifetime recreational gamblers: } 28.7 \%, 0.85 \% \\
\text { Higher medical, addictive and psychiatric } \\
\text { comorbidities in PG }\end{array}$ \\
\hline USA & Pietrzak et al. & 2006 & $N=3160+$ & Quantitative study & $\begin{array}{l}75 \% \text { of pathological and } 30 \% \text { of problem } \\
\text { gamblers interested in gambling treatment } \\
\text { Problem gambling induces increased } \\
\text { psychological distress in older adults }\end{array}$ \\
\hline USA & Pilver et al. & 2016 & $N=10,56355+$ & Quantitative study & $\begin{array}{l}\text { Gambling positive activity for older adults but risky } \\
\text { and PG associated with psychiatric disorders }\end{array}$ \\
\hline USA & Piscitelli et al. & 2017 & $N=2,10355+$ & Quantitative study & $\begin{array}{l}18.5 \% \text { would visit a casino, stay longer, and } \\
\text { spend more money if new casino open close to } \\
\text { them }\end{array}$ \\
\hline USA & Potenza et al. & 2006 & $N=1,01855+$ & Quantitative study & $\begin{array}{l}\text { Older gamblers: Lower income, lower duration } \\
\text { of gambling, fewer types of gambling, more } \\
\text { problems with slot machines }\end{array}$ \\
\hline USA & Singh et al. & 2007 & $\begin{array}{c}\mathrm{N}=30065 \\
\text { (mean) }\end{array}$ & Quantitative study & $\begin{array}{l}\text { Parkinson and gambling Patients with PG younger } \\
\text { than other patients }\end{array}$ \\
\hline Australia & Southwell et al. & 2008 & $N=41460+$ & Quantitative study & $\begin{array}{l}\text { Predictors of PG: Younger, male, single, motivated } \\
\text { to play EGMs (excitement/to win money) } 27 \% \\
\text { reported drawing on their savings to gamble }\end{array}$ \\
\hline Singapore & Tse et al. & 2013 & $\mathrm{~N}=3,01055+$ & Quantitative study & $\begin{array}{l}39.2 \% \text { gambled in the past year; } 0.9 \% \text { had PG } \\
\text { ( } 2.2 \% \text { of the population of lifetime gamblers). } \\
\text { Type of gambling: continuity without set limits to } \\
\text { amount wagered }\end{array}$ \\
\hline USA & Vanderbilt J. et al. & 2004 & $N=1,01670+$ & Quantitative study & $\begin{array}{l}47.7 \% \text { reported gambling. Gambling: a form } \\
\text { of social support. Younger age, greater social } \\
\text { support, alcohol use in the past year associated } \\
\text { with gambling activity }\end{array}$ \\
\hline Canada & Van der Maas, et al. & 2017 & $N=1,97855+$ & Quantitative study & $\begin{array}{l}\text { Using bus tours to access Canadian gambling } \\
\text { venues associated with risk of PG. Bus tours } \\
\text { patrons likely to be: female, over } 75 \text { years old, } \\
\text { born outside Canada }\end{array}$ \\
\hline Canada & Wiebe et al. & 2005 & $N=1,00060+$ & Quantitative study & $\begin{array}{l}74.7 \% \text { gambled in the past year, } 1.6 \% \text { problem } \\
\text { gambling. South Oaks Gambling Screen - R: } \\
\text { needs to be refined for use with older adults }\end{array}$ \\
\hline USA & Zaranek et al. & 2005 & $N=1,41060+$ & Quantitative study & $\begin{array}{l}\text { Majority of social gamblers } 17.2 \% \text { visited the } \\
\text { casino monthly or more frequently Positive } \\
\text { attitudes about casinos }\end{array}$ \\
\hline USA & Zaranek et al. & 2008 & $N=1,41060+$ & Quantitative study & $\begin{array}{l}\text { Problem gambling: } 10.4 \%, 18 \% \text { among those } \\
\text { reporting casino visits }\end{array}$ \\
\hline
\end{tabular}

Older adults with a life-long history of problem gambling had experienced significantly more medical problems in the previous year (1). Problem gambling is associated with chronic medical illness (24). Pietrzak et al. showed that, among medical morbidities in older adults with PG, angina and arthritis were overrepresented (25) and both reduce the physical abilities of older adults. Problem gambler status is significantly associated with a lower quality of life, in medical, social, and emotional terms, compared with social gamblers or non-gamblers. They have a more negative perception of their general and psychological state and a more pessimistic view of their future state of health $(26,27)$. Desai et al. (32) showed, in data from the NESARC (National Epidemiologic Survey on Alcohol and Related Conditions), that subjects over 65 years of age, with a history of problem gambling during the year, had significantly more alcohol use disorders and were more frequently tobacco dependent (24). Life-long problem gambling was associated with substance use disorders (alcohol, illicit substances), but also with psychiatric disorders: mood disorders (depression, dysthymia, mania, hypomania) and anxiety disorders or avoidant personality disorder $(25,28)$. In older adults, cognitive impairment may also reduce the ability to decide to stop gambling (29), especially in cognitive impairment which involves the frontal cortex (as in frontotemporal lobar degeneration).

Specific attention should be paid to the complex and varied relationship between gambling and Parkinson's disease (PD) and dopaminergic medication (30). Impulse control disorders (ICDs), such as compulsive gambling, and also buying, sexual, and eating behaviors, are a serious, recognized complication in PD which occurs in up to $20 \%$ of PD patients over the course of their illness and especially in those with the highest risk profile (31).

\section{Social and Financial Determinants}

Several studies identify socio-professional, financial, and educational status as risk factors for problem gambling $(1,23)$. This connection 


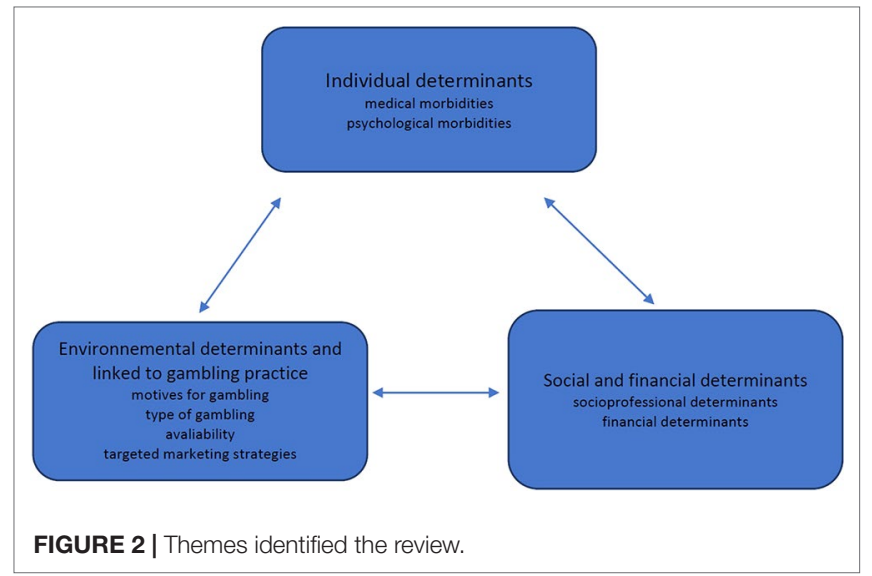

TABLE 3 | Specificities of gambling characteristics in older adults.

\begin{tabular}{|c|c|}
\hline & Older adults \\
\hline GD screen tools & $\begin{array}{l}\text { No specific tools Less specificity of criteria : } \\
\text { occupational / social consequences }\end{array}$ \\
\hline GD lifetime prevalence & $\begin{array}{l}0.01-10.6 \% \text { (Subramaniam, 2016) Percentage of } \\
\text { pathological gambling decreasing with age beyond } \\
60\end{array}$ \\
\hline $\begin{array}{l}\text { Gambling determinants } \\
\text { Individuals }\end{array}$ & Women over 60 years old \\
\hline Social determinants & $\begin{array}{l}\text { Losses, isolation, lower and fixed income, } \\
\text { retirement }\end{array}$ \\
\hline Motives for gambling & $\begin{array}{l}\text { Entertainment, enjoyment Combat boredom, } \\
\text { fight against negative emotional states, fills a void } \\
\text { Social connections, substitution for social support } \\
\text { Improving cognitive skills }\end{array}$ \\
\hline $\begin{array}{l}\text { Gambling } \\
\text { characteristics }\end{array}$ & $\begin{array}{l}\text { Expansion of legal market, availability, accessibility } \\
\text { Targeted, intrusive marketing strategies Type of } \\
\text { gambling: casino, continuous and limitless games } \\
\text { (for PG) }\end{array}$ \\
\hline
\end{tabular}

is not found in all studies (22) but it should be taken into account, particularly with regard to the elderly. Older people are especially vulnerable to gambling related problems due to loss experienced in their personal life: loss of role, loneliness, social isolation, and a lower or fixed income. The change in professional status with retirement can have a direct influence on a gambler's behavior. A decline in income in retirement can be a factor which precipitates the passage from social gambling behavior to problem gambling. Gamblers may wish to make up for a loss of income through winnings from gambling by increasing their participation $(26,37)$. The moneymaking motivation, combined with the search for excitement, have been identified as predictors of risk and problem gambling among slot-machine gamblers over the age of 60 (38). In addition, the failure to adjust their betting in proportion to their lower income in retirement may also lead to difficulties.

\section{Determinants Correlated to Gambling Cognitive Distortions}

Cognitive distortions, found in younger adults (63), have also been identified in older adults. In a multi-ethnic Asian sample of gamblers, Subramaniam et al. identified the following themes in the perception of gambling: skill, near miss, concept of luck, superstitious beliefs, entrapment, gambler's fallacy, chasing wins, chasing losses, and the belief that wins exceeded losses. These gambling-related cognitions played a role in the maintenance and escalation of gambling (39).

The type and structural characteristics of gambling may enhance cognitive distortions. Lottery video terminals and slot machines have used a computer and virtual reels to determine the odds. Since the end of the eighties, a clustering technique has been used to create a high number of near misses (64). What the gamblers see on the machine does not correspond to reality and it induces a misperception of the probability of winning; gamblers take the near miss as an indication of their improving skills which leads to gambling behavior being sustained (65).

It could be interesting to analyse older problem gamblers' cognition to identify strategic prevention targets. A reduction in gambling cognitive distortions was identified as being one of the best predictors of recovery (66).

\section{Motives for Gambling}

Eighty percent of older gamblers are looking for entertainment and enjoyment $(5,67)$. Thirty-eight percent say they gamble to distract themselves from everyday problems, and combat boredom but also loneliness $(32,34,58)$. Studies in North America show that older people frequently visit gambling locations (casinos) to make social connections (2). Living alone and/or being separated, divorced or socially isolated are factors associated with problem gambling (1).

Access to stimulating activities for leisure and pleasure are likely to be reduced with age and some people may not be able to participate in activities they had previously enjoyed $(1,54)$. One hypothesis is that gambling fills a void in the lives of older people and may be a form of substitute for social support (33).

The fight against negative emotional states (68), linked to loss or grief, is one of the factors motivating gambling activity $(3,67)$. However, gambling is not always a problem: improving cognitive skills is one of the motives for gambling. A general population study has even shown that people who had gambled during the past year had better subjective health than those who had not gambled (69).

\section{Type of Gambling}

Casino trips are the first outside activity offered to institutionalized elderly people (67). Over 65 s account for $39 \%-45 \%$ of all casino users. In terms of casino use, the prevalence of pathological gambling ranges from $6.7 \%$ (never) to $19.1 \%$ (at least once a month) in a study conducted among non-institutionalized elderly subjects (33).

The use of gambling varies among older subjects according to the characteristics of the type of gambling practiced. The perception of harm associated with gambling products is high in the general population; casino and EGMs are identified as very, or extremely, harmful by the general population. According to TSE et al. in 2013, problem gamblers over the age of 55 tend to play continuous or limitless games such as slot machines, online games or even scratch games, while those without a gambling problem tend to play discontinuous, inexpensive and time-limited 
games such as lotteries. However, there are few studies so far on the structural characteristics or the different types of games (pure chance games or those involving skill) which are popular with the elderly (3).

\section{The Availability of Gambling Opportunities}

One of the factors highlighted by this increase in gambling behavior is the expansion of the legal gambling market, especially with developments in Internet gambling. The global gambling market was estimated to be worth 430 billion US dollars in 2012 (Global Gambling and Gaming Consultants). Several studies have highlighted the links between the availability and proximity of gambling opportunities and excessive gambling practices (8, 70). A study on socio-cultural factors among gamblers over 60 years of age showed that, in problem gambling populations in need of care, the age at initiation and the desire to gamble were much higher in the United States than in Brazil (53). One of the authors' hypotheses is that the availability of gambling, as a result of each state's legislation, is much more significant in the USA than in Brazil. The legislative framework for gambling can thus have a direct impact on gambling practices (53), especially among vulnerable people.

Gambling is part of a growing industry driven by powerful multi-national corporations. There is an intensification in marketing strategies which target older people (26). Older adults are an especially desirable demographic for the gambling industry because they fill the floors during off-peak hours. Casinos aggressively direct marketing towards them, offering discounts on meals, free drinks, and guarantees to win and, sometimes, medication discount coupons. Some gambling locations also offer transportation for people coming to the casino (71). A recent study showed that, among older adults, using bus tours to access gambling venues was associated with an increased risk of problem gambling $(28,60)$.

Loyalty strategies are being implemented by many casinos in France which offer a "VIP" upgrade to gamblers. The gambling opportunities offered at casinos are described as the ideal solution for the "needs of seniors", and several countries are trying to raise awareness of this intrusive marketing campaign which targets vulnerable, elderly people $(67,72)$.

The targeted gamblers most susceptible to these offers (bus tours) tend to be retired women, over 75 years of age $(28,60)$. Older women seem to be more vulnerable to gambling marketing strategy and, more particularly, to electronic games machines (73). Specific gambling characteristics in older adults are synthetised in Table 3.

\section{DISCUSSION}

In a large majority of studies, gambling in older people is compared with gambling in a younger population in employment. Through the analysis of the selected articles, clear gambling specificities in older adults were identified: first, individual specificities; second, social and financial specificities; and third, those correlated with gambling.

Individual determinants, concerning gender and age and morbidities could make it possible for caregivers for the elderly to identify GD in this population and offer guidance. Chronic medical illness, $(32,43)$, substance use disorders, but also mood disorders, anxiety disorders or avoidant personality disorder $(43,55)$, cognitive impairment (49) or PD (49) are risk factors for GDs (74). Social and financial determinants are also specific keys to GDs in older adults. Retirement is a moment when some are at risk, particularly at risk of failure to adjust their betting in proportion to their lower income (26, 45). Disordered gambling may increase financial problems, including credit card and other debts (75). A reduced ability to deal with the damage caused by their gambling is one particular specificity in older adults. Lack of resources to cover the damaging level of gambling expenditure appears to be specific to older adults. They have less time and fewer financial resources to recover from social, financial and, particularly, the medical and psychiatric consequences resulting from disordered gambling. Therefore, the identification of GDs is not initially concerned with medical care and so other types of action could be required to help gamblers to control or to stop their habit. Family support, for example, is very important: a recent study showed that, among older gamblers, family support was essential in helping to implement control strategies for responsible gambling (40). To help identify GD in vulnerable older people, Kerber et al. proposed the acronym "CASINO" to help everyone to remember the impact and factors linked to disordered gambling in older adults: Chronic health problems, Affective disorders, Serious risk of suicide, Incarceration, NO money, credit card debts, and financial problems (57). This acronym includes individual and social determinants.

One main point of this review is that it underlines the influence of determinants correlated with gambling. Gambling type, as well as gambling-targeted offers and availability, reinforce gambling motivation and cognitive distortions in older people. An editorial in the journal, Nature, underlined recently that gambling in vulnerable populations is a public health concern. They asked: how can research help the unfortunate minority who cross to gambling's dark side? They also drew attention to the lack of scientific studies on the subject and to the lack of debate about society taking control of an industry which profits from compulsive gambling much more than from occasional gambling (76). In 2009, Moodie and Hastings pointed out that public health authorities could learn a great deal from tobacco control, in terms of how to respond to gambling (77). Caregivers and public health authorities should be aware of specific points concerning gambling practices in older adults. Gambling can be extremely attractive and easily available to the elderly. All gambling marketing variables are adapted to fit older people's needs and vulnerabilities and to increase gambling activity.

Casinos and other gambling locations know how to meet the specific needs of older people. Isolation and boredom are risk factors for GD in older adults. Public authorities and institutions taking care of older people should consider that to delegate the provision of social activities for older people to gambling locations, as defined in literature, may not be an ideal solution and may not demonstrate a responsible or fair attitude towards older people. Social or leisure activities could be developed which are suited to older adults and which would help to limit 
casino attendance and reduce harm. Gambling locations direct extensively aggressive marketing towards older people.

The extent to which these assisted living facilities should encourage older adults to gamble increasingly and whether they should be liable for increasing the financial risks of the residents are matters to be addressed. The risk is especially important if one fails to identify gambling problems in older adults.

\section{Limitations}

Due to the lack, in current literature, of specific analysis on elderly gamblers, literature review, case reports, qualitative, and quantitative studies were included in this systematic review. It induces a high level of heterogeneity of data.

Results of this review are limited by three bias, which limits comparison of data. We identified selection bias in selected studies and cultural bias, as a majority of studies concern North America. An evaluation bias was also identified, it concerned the definition of problem gambling or GD in older people, which differed in articles. It raised problems in comparing and analyzing the existing data.

\section{IMPLICATIONS AND CONCLUSION}

A wide variety of treatment options is available for gamblers who seek help and treatment: phone lines (psychiatric emergencies or gambling helpline), associations (e.g., Gamblers Anonymous), outpatient treatment (private therapists, community mental health centers or addictive disorders centers) but also general practitioners and, sometimes, in-patient addiction recovery centers. Very few older people with a GD will seek access to specific treatment

\section{REFERENCES}

1. Subramaniam M, Wang P, Soh P, Vaingankar JA, Chong SA, Browning CJ. Prevalence and determinants of gambling disorder among older adults: a systematic review. Addict Behav (2015) 41:199-209. doi: 10.1016/j. addbeh.2014.10.007

2. Zaranek RR, Chapleski EE. Casino gambling among urban elders: just another social activity?. J Gerontol B Psychol Sci Soc Sci (2005) 60(2):S74-81. doi: $10.1093 /$ geronb/60.2.S74

3. Tse S, Hong SI, Ng KL. Estimating the prevalence of problem gambling among older adults in Singapore. Psychiatry Res (2013) 210(2):607-11. doi: 10.1016/j.psychres.2013.06.017

4. Wardle H, Moody A, Spence S. Orford, J. Volberg, R. Jotangia D. et al. British gambling prevalence survey. (2010). National centre for social research; National report for gambling commission 189.

5. Martin F, Lichtenberg PA, Templin TN. A longitudinal study: casino gambling attitudes, motivations, and gambling patterns among urban elders. J Gambl Stud (2011) 27(2):287-97. doi: 10.1007/s10899-010-9202-4

6. Tse S, Hong SI, Wang CW, Cunningham-Williams RM. Gambling behavior and problems among older adults: a systematic review of empirical studies. J Gerontol B Psychol Sci Soc Sci (2012) 67(5):639-52. doi: 10.1093/geronb/ gbs068

7. Volberg RA, Abbott MW, Ronnberg S, Munck IM. Prevalence and risks of pathological gambling in Sweden. Acta Psychiatr Scand (2001) 104(4):250-6. doi: 10.1111/j.1600-0447.2001.00336.x

8. Vander Bilt J, Dodge HH, Pandav R, Shaffer HJ, Ganguli M. Gambling participation and social support among older adults: a longitudinal programs. Therefore, to reduce harm, especially financial, social, and psychological harm, family and social services have a principal role to play and a protective legislative measure could be discussed. However, policies concerning gambling control are still insufficient for helping vulnerable gamblers to reduce their gambling activities.

According to literature, it seems that older adults are gambling more and more and that the proportion of pathological gamblers is increasing in this age group. The findings of this current review support the need to consider the determinants of gambling in this group. Pathological gambling among older adults is associated with medical, psychiatric, and social comorbidities. The types of motivation for gambling in older adults involve the search for entertainment and the fight against boredom and loneliness. It has the potential to cause extreme harm because of a lack of resources to recover from the negative consequences of gambling. Many studies underline vulnerabilities, especially those linked to the environment and to gambling. Public health authorities and societies should take these findings into account. Gambling policies should help vulnerable gamblers to better control the habit and to reduce harm caused by gambling. There is a need to question the responsibility of public health authorities, as well as the lack of legislation and social measures to control gambling marketing strategies and gambling availability targeting vulnerable people. As with other addictions, responsible governments need to balance tax revenue against a duty of care towards vulnerable members of society (78)

\section{AUTHOR CONTRIBUTIONS}

MGL, JC, and MGB carried out the systematic search of bibliographic databases, and reviewed all the articles. MGL, JC, and MGB wrote the article. SL and JR reviewed and revised the article.

community study. J Gambl Stud (2004) 20(4):373-89. doi: 10.1007/ s10899-004-4580-0

9. Philippe F, Vallerand RJ. Prevalence rates of gambling problems in Montreal, Canada: a look at old adults and the role of passion. J Gambl Stud (2007) 23(3):275-83. doi: 10.1007/s10899-006-9038-0

10. Lai DW. Gambling and the older Chinese in Canada. : J Gambling Stud (2006) 22(1):121-41. doi: 10.1007/s10899-005-9006-0

11. Costes J-M, Kairouz S, Eroukmanoff V, Monson E. Gambling Patterns and Problems of Gamblers on Licensed and Unlicensed Sites in France. J Gambl Stud (2015). doi: 10.1007/s10899-015-9541-2

12. Martins S, Storr CL, Lee GP, Lalongo LS. Environmental influences associated with gambling in young adulthood. J urban Health : Bull New York Acad Med (2013) 90:130-40. doi: 10.1007/s11524-012-9751-1

13. Welte JW, Barnes GM, Wieczorek WF, Tidwell M-CO, Parker JC. Risk factors for pathological gambling. Addict Behav (2004) 29(2):323-35. doi: 10.1016/j. addbeh.2003.08.007

14. Bruneau M, Grall-Bronnec M, Venisse JL, Romo L, Valleur M, Magalon D. Gambling transitions among adult gamblers: A multi-state model using a Markovian approach applied to the JEU cohort. Addict Behav (2016) 57:1320. doi: 10.1016/j.addbeh.2016.01.010

15. Ibáñez A, Blanco C, Donahue E, Lesieur HR, Pérez de Castro I, Fernández-Piqueras J. Psychiatric comorbidity in pathological gamblers seeking treatment. Am J Psychiatry (2001) 158(10):1733-5. doi: 10.1176/ ajp.158.10.1733

16. Petry NM, Steinberg KL, Women's Problem Gambling Research C. Childhood maltreatment in male and female treatment-seeking pathological gamblers. Psychol Addict Behav (2005) 19(2):226-9. doi: 10.1037/0893-164X.19.2.226 
17. Blanco C, Myers J, Kendler KS. Gambling, disordered gambling and their association with major depression and substance use: a web-based cohort and twin-sibling study. Psychol Med (2012) 42(3):497-508. doi: 10.1017/ S0033291711001401

18. Levesque D, Sevigny S, Giroux I, Jacques C. Psychological Vulnerability and Problem Gambling: The Mediational Role of Cognitive Distortions. J Gambl Stud (2018) 34(3):807-22. doi: 10.1007/s10899-017-9740-0

19. Guillou-Landreat M, Guilleux A, Sauvaget A, Brisson L, Leboucher J, Remaud M. Factors associated with suicidal risk among a French cohort of problem gamblers seeking treatment. Psychiatry Res (2016) 240:11-8. doi: 10.1016/j.psychres.2016.04.008

20. Moccia L, Pettorruso M, De Crescenzo F, De Risio L, di Nuzzo L, Martinotti G. Neural correlates of cognitive control in gambling disorder: a systematic review of fMRI studies. Neurosci Biobehav Rev (2017) 78:104-16. doi: 10.1016/j.neubiorev.2017.04.025

21. Pettorruso M, Martinotti G, Cocciolillo F, De Risio L, Cinquino A, Di Nicola M. Striatal presynaptic dopaminergic dysfunction in gambling disorder: A (123) I-FP-CIT SPECT study. Addict Biol (2019) 24(5):1077-86. doi: 10.1111/adb.12677

22. Dreher JC, Meyer-Lindenberg A, Kohn P, Berman KF. Age-related changes in midbrain dopaminergic regulation of the human reward system. Proc Natl Acad Sci U S A (2008) 105(39):15106-11. doi: 10.1073/pnas.0802127105

23. Ledgerwood DM, Petry NM. Gambling and suicidality in treatmentseeking pathological gamblers. J Nerv Ment Dis (2004) 192(10):711-4. doi: 10.1097/01.nmd.0000142021.71880.ce

24. Petry NM. A comparison of young, middle-aged, and older adult treatmentseeking pathological gamblers. Gerontologist (2002) 42(1):92-9. doi: 10.1093/geront/42.1.92

25. Potenza MN, Steinberg MA, Wu R, Rounsaville BJ, O'Malley SS. Characteristics of older adult problem gamblers calling a gambling helpline. J Gambl Stud (2006) 22(2):241-54. doi: 10.1007/s10899-006-9013-9

26. Tira C, Jackson AC, Tomnay JE. Pathways to late-life problematic gambling in seniors: a grounded theory approach. Gerontologist (2014) 54(6):1035-48. doi: 10.1093/geront/gnt107

27. Christensen MH, Patsdaughter CA. Gambling behaviors in Black older adults: perceived effects on health. J Gerontol Nurs (2004) 30(4):34-9. doi: 10.3928/0098-9134-20040401-08

28. van der Maas M, Mann RE, Matheson FI, Turner NE, Hamilton HA, McCready J. A free ride? An analysis of the association of casino bus tours and problem gambling among older adults. Addict (2017) 112(12):2217-24. doi: 10.1111/add.13914

29. Pilver CE, Libby DJ, Hoff RA, Potenza MN. Problem gambling severity and the incidence of Axis I psychopathology among older adults in the general population. J Psychiatr Res (2013) 47(4):534-41. doi: 10.1016/j. jpsychires.2012.12.013

30. Nower L, Blaszczynski A. Characteristics of problem gamblers 56 years of age or older: a statewide study of casino self-excluders. Psychol Aging (2008) 23(3):577-84. doi: 10.1037/a0013233

31. Piscitelli A, Harrison J, Doherty S, Carmichael BA. Older Adults' Casino Gambling Behavior and Their Attitudes Toward New Casino Development. Int J Aging Hum Dev (2017) 84(4):415-30. doi: 10.1177/ 0091415016677973

32. Desai RA, Desai M, Potenza M. Gambling, health and age: Data from the National Epidemiologic survey on Alcohol and Related conditions. Psychol Addictive Behav (2007)(21), 431-40. doi: 10.1037/0893-164X.21.4.431

33. Zaranek RR, Lichtenberg PA. Urban elders and casino gambling: Are they at risk of a gambling problem?. J Aging Stud (2008) 22(1):13-23. doi: 10.1016/j. jaging.2007.11.001

34. Pietrzak RH, Petry NM. Severity of gambling problems and psychosocial functioning in older adults. J Geriatr Psychiatry Neurol (2006) 19(2):106-13. doi: $10.1177 / 0891988706286508$

35. Wiebe JM, Cox BJ. Problem and probable pathological gambling among older adults assessed by the SOGS-R. J Gambl Stud (2005) 21(2):205-21. doi: 10.1007/s10899-005-3032-9

36. Erickson L, Molina CA, Ladd GT, Pietrzak RH, Petry NM. Problem and pathological gambling are associated with poorer mental and physical health in older adults. Int J Geriatr Psychiatry (2005) 20(8):754-9. doi: 10.1002/ gps. 1357
37. Kausch O. Pathological gambling among elderly veterans, J Geriatr Psychiatry Neurol (2004) 17(1):13-9. doi: 10.1177/0891988703261999

38. Black DW, Coryell W, McCormick B, Shaw M, Allen J. A prospective follow-up study of younger and older subjects with pathological gambling. Psychiatry Res (2017) 256:162-8. doi: 10.1016/j.psychres. 2017.06.043

39. Subramaniam M, Chong SA, Browning C, Thomas S. Cognitive distortions among older adult gamblers in an Asian context. PloS One (2017) 12(5):e0178036. doi: 10.1371/journal.pone.0178036

40. Subramaniam M, Satghare P, Vaingankar JA, Picco L, Browning CJ, Chong SA. Responsible gambling among older adults: a qualitative exploration. BMC Psychiatry (2017) 17(1):124. doi: 10.1186/s12888-017-1282-6

41. Subramaniam M, Chong SA, Satghare P, Browning CJ, Thomas S. Gambling and family: A two-way relationship. J Behav Addict. (2017) 6(4):689-98. doi: $10.1556 / 2006.6 .2017 .082$

42. Sauvaget A, Jimenez-Murcia S, Fernandez-Aranda F, Fagundo AB, Moragas L, Wolz I. Unexpected online gambling disorder in late-life: a case report. Front Psychol (2015) 6:655. doi: 10.3389/fpsyg.2015.00655

43. Pietrzak R, Morasco B, Blanco C, Grant B, Petry N. Gamblig level and psychiatric and medical disorders in older adults : results from the National Epidemiologic Sirvey on Alcohol and Related conditions. Am J Geriatric Psychiatry (2007) 15(4):301-13. doi: 10.1097/01.JGP.0000239353.40880.cc

44. Southwell J, Boreham P, Laffan W. Problem gambling and the circumstances facing older people : a study of gaming machine players aged $60+$ in licensed clubs. J Gambl Stud (2008) 24(2):151-74. doi: 10.1007/s10899-007-9079-z

45. Botterill E, Gill PR, McLaren S, Gomez R. Marital Status and Problem Gambling Among Australian Older Adults: The Mediating Role of Loneliness. J Gambl Stud (2016) 32(3):1027-38. doi: 10.1007/ s10899-015-9575-5

46. McNeilly DP, Burke WJ. Late life gambling: the attitudes and behaviors of older adults. J Gambl Stud (2000) 16(4):393-415. doi: 10.1023/ A: 1009432223369

47. Cousins SO, Witcher CS. Who plays bingo in later life? The sedentary lifestyles of 'little old ladies'. J Gambl Stud (2007) 23(1):95-112. doi: 10.1007/ s10899-006-9030-8

48. Wood S, Busemeyer J, Koling A, Cox CR, Davis H. Older adults as adaptive decision makers: evidence from the Iowa Gambling Task. Psychol Aging (2005) 20(2):220-5. doi: 10.1037/0882-7974.20.2.220

49. Levens S, Dyer AM, Zubritsky C, Knott K, Oslin DW. Gambling among older, primary-care patients: an important public health concern. Am J Geriatr Psychiatry (2005) 13(1):69-76. doi: 10.1097/00019442-200501000-00010

50. Desai RA, Maciejewski PK, Dausey DJ, Caldarone BJ, Potenza MN. Health correlates of recreational gambling in older adults. Am J Psychiatry (2004) 161(9):1672-9. doi: 10.1176/appi.ajp.161.9.1672

51. Burge AN, Pietrzak RH, Molina CA, Petry NM. Age of gambling initiation and severity of gambling and health problems among older adult problem gamblers. Psychiatr Serv (2004) 55(12):1437-9. doi: 10.1176/appi. ps.55.12.1437

52. Ladd GT, Molina CA, Kerins GJ, Petry NM. Gambling participation and problems among older adults. J Geriatr Psychiatry Neurol (2003) 16(3):1727. doi: $10.1177 / 0891988703255692$

53. Medeiros GC, Leppink E, Yaemi A, Mariani M, Tavares H, Grant J. Gambling disorder in older adults : a cross cultural perspective. Compr Psychiatry (2015) 58:116-21. doi: 10.1016/j.comppsych.2014.12.021

54. Parke A, Griffiths M, Pattinson J, Keatley D. Age-related physical and psychological vulnerability as pathways to problem gambling in older adults. J Behav Addict (2018) 7(1):137-45. doi: 10.1556/2006.7.2018.18

55. Kerber CS, Black DW, Buckwalter K. Comorbid psychiatric disorders among older adult recovering pathological gamblers. Issues Ment Health Nurs (2008) 29(9):1018-28. doi: 10.1080/01612840802274933

56. Kerber CS, Schlenker E, Hickey K. Does your older adult client have a gambling problem?. J Psychosoc Nurs Ment Health Serv (2011) 49(6):38-43. doi: 10.3928/02793695-20110503-04

57. Kerber C, Adelman-Mullally T, Kim M, Astroth KS. The Impact of Disordered Gambling Among Older Adults. J Psychosoc Nurs Ment Health Serv (2015) 53(10):41-7. doi: 10.3928/02793695-20150923-03

58. Pattinson J, Parke A. The experience of high-frequency gambling behavior of older adult females in the United Kingdom: An interpretative 
phenomenological analysis. J Women Aging (2017) 29(3):243-53. doi: 10.1080/08952841.2015.1138047

59. Papineau E, Lemetayer F, Lasnier B, Giguère N. Les jeux de hasard et d'argent et les aînés: perspectives des intervenants sur les risques, les impacts et la prévention. Institut National de sante publique du Quebec (INSPQ) - 97 p. ; Montréal, Québec (2014).

60. Boisvert Y, Papineau E, Lesemann F. L’offre organisée de jeux de hasard et dargent aux ainés: responsabilité sociale, gouvernance et prévention. Montréal: Quebec. Conseil des aînés, MSSS, le Secrétariat aux ainés, l'AQRP et le FQRSC (2012).

61. American Psychiatric A. Diagnostic and statistical manual of mental disorders. American psychiatric Association. Washington, DC : American Psychiatric Association. 2013 (2013). doi: 10.1176/appi.books.9780890425596

62. Smith M, Hategan A, Bourgeois JA. Geriatric gambling disorder: challenges in clinical assessment. Int Psychogeriatr (2017) 29(12):1-2. doi: 10.1017/ S1041610217001843

63. Blaszczynski A, Nower L. A pathways model of problem and pathological gambling.Addiction. (2002) 97(5):487-99. doi: 10.1046/j.1360-0443.2002.00015.x

64. Harrigan KA. Slot Machines: Pursuing Responsible Gaming Practices for Virtual Reels and Near Misses. Int J Ment Health Addict (2009) 7(1):68-83. doi: 10.1007/s11469-007-9139-8

65. Billieux J, Van der Linden M, Khazaal Y, Zullino D, Clark L. Trait gambling cognitions predict near-miss experiences and persistence in laboratory slot machine gambling. Br J Psychol (2012) 103(3):412-27. doi: 10.1111/j.2044-8295.2011.02083.x

66. Rossini-Dib D, Fuentes D, Tavares H. A naturalistic study of recovering gamblers: What gets better and when they get better. Psychiatry Res (2015) 227(1):17-26. doi: 10.1016/j.psychres.2015.03.003

67. Luquiens A. Il n' y a pas d'âge pour jouer trop. Neurol Psychiatr Gériatr (2016). 16(95):243-5. doi: 10.1016/j.npg.2016.04.005. sous presse.

68. Clarke D. Older adults' gambling motivation and problem gambling: a comparative study. J Gambl Stud (2008) 24(2):175-92. doi: 10.1007/ s10899-008-9090-z

69. Martins S, Ghandour L, Storr C. Gambling behavior subtypes among respondents with gambling related problems in a population based sample. $J$ Addict Dis (2011) 30:169-80. doi: 10.1080/10550887.2011.554781

70. Guillou Landreat M., Grall Bronnec M. Facteurs de risque socio environnementaux. In: Masson E, Grall Bronnec Meditors. Le jeu pathologique: comprendre, prévenir, traiter Paris. (Paris, France : Eslevier Masson) (2012). p. 176. doi: 10.1016/B978-2-294-72671-2.00010-6
71. Dyall L, Tse S, Kingi A. Cultural icons and marketing of gambling. Internation J Ment Health Addict (2009) 7:84-96. doi: 10.1007/s11469-007-9145-x

72. Boisvert Y, Lesemann F, Papineau E. Boisvert Y, Lesemann F, Papineau E L'offre rganisée de jeux de hasard et d'argent aux aînés : responsabilité sociale, gouvernance et prévention Québec 2009..

73. Mc Kay C. Double jeopardy : older women and problem gambling. Int J Ment Heal Addict (2005) 3:35-53. doi. 10.11575/PRISM/9488

74. Weintraub D, Claassen DO. Impulse Control and Related Disorders in Parkinson's Disease. Int Rev Neurobiol (2017) 133:679-717. doi: 10.1016/ bs.irn.2017.04.006

75. Volberg RA. Gambling and problem gambling among seniors in Florida: Report to the Florida Council on Aging. Northampton, MA: Gemini Research Ltd. (2003).

76. Science has a gambling problem. Nature. (2018) 553(7689):379. doi: 10.1038/ d41586-018-01051-z

77. Moodie C, Hastings G. Social marketing and problem gambling: a critical perspective. Addict (2009) 104(5):692-3; discussion 7-8. doi: 10.1111/j.1360-0443.2008.02482.x

78. The Lancet. The L. Problem gambling is a public health concern. Lancet (2017) 390(10098):913. doi: 10.1016/S0140-6736(17)32333-4

Conflict of Interest: MGB and JC declare that the University Hospital of Nantes has received funding from the gambling industry (FDJ and PMU) in the form of a sponsorship that supports the gambling section of the BALANCED Unit (the Reference Center for Excessive Gambling). We guarantee that this review is scientifically independent of the gambling industry operators. There were no constraints on publishing.

The remaining authors declare that the research was conducted in the absence of any commercial or financial relationships that could be construed as a potential conflict of interest.

Copyright (๐) 2019 Guillou Landreat, Cholet, Grall Bronnec, Lalande and Le Reste. This is an open-access article distributed under the terms of the Creative Commons Attribution License (CC BY). The use, distribution or reproduction in other forums is permitted, provided the original author(s) and the copyright owner(s) are credited and that the original publication in this journal is cited, in accordance with accepted academic practice. No use, distribution or reproduction is permitted which does not comply with these terms. 